\title{
Análise genética e fenotípica em progênies de polinização livre de Mimosa caesalpiniifolia Benth.: implicações para melhoramento genético
}

Genetic and phenotypic analysis in free-pollination progenies of Mimosa caesalpiniifolia Benth.: implications for genetic improvement

Análisis genético y fenotípico en progenies de polinización libre de Mimosa caesalpiniifolia Benth.: implicaciones para la mejora genética

Fernando dos Santos Araújo

ORCID: https://orcid.org/0000-0002-0605-1613 Universidade Federal da Paraíba, Brasi E-mail: nandosantos005@hotmail.com

Francival Cardoso Felix

ORCID: https://orcid.org/0000-0002-6518-5697 Universidade Federal do Paraná, Brasi E-mail: felixfc@outlook.com.br

Richeliel Albert Rodrigues Silva

ORCID: https://orcid.org/0000-0002-8098-4155

Universidade Estadual do Centro-Oeste, Brasil E-mail: richeliel@yahoo.com.br

Luiz Augusto da Silva Correia

ORCID: https://orcid.org/0000-0002-1333-8364 Universidade Federal do Rio Grande do Norte, Brasil E-mail: lasc.eng@gmail.com

Josenilda Aprígio Dantas de Medeiros ORCID: https://orcid.org/0000-0001-5759-6771 Universidade Federal do Rio Grande do Norte, Brasil E-mail: josi-nilda@hotmail.com

Cibele dos Santos Ferrari

ORCID: https://orcid.org/0000-0003-2940-0190 Universidade Federal do Rio Grande do Norte, Brasil E-mail: cibeferrari@hotmail.com

Fábio de Almeida Vieira

ORCID: https://orcid.org/0000-0003-3347-255X Universidade Federal do Rio Grande do Norte, Brasil E-mail: vieirafa@gmail.com

Mauro Vasconcelos Pacheco

ORCID: https://orcid.org/0000-0002-0447-9800 Universidade Federal do Rio Grande do Norte, Brasil

E-mail: pachecomv@hotmail.com

Roberta de Lima Valença

ORCID: https://orcid.org/0000-0003-1341-1602 Universidade Federal do Agreste de Pernambuco, Brasil

E-mail: robertalimav@hotmail.com

\section{Resumo}

Mimosa caesalpiniifolia Benth. (Fabaceae) é uma árvore nativa da região semiárida do Nordeste do Brasil que apresenta potencial econômico crescente para exploração de produtos florestais madeireiros e não-madeireiros. A presença de acúleos agressivos na maioria destas plantas dificulta o manejo dos povoamentos, mas existem exemplares sem acúleos que podem ser utilizados para contornar este inconveniente. Assim, objetivou-se determinar a frequência fenotípica do caráter ausência/presença de acúleos em progênies de polinização livre de uma população cultivada de $M$. caesalpiniifolia e acessar a diversidade genética de indivíduos do fenótipo sem acúleos desta população. A diversidade genética foi acessada usando marcadores moleculares Inter Simple Sequence Repeat (ISSR) e a fenotipagem quanto à presença/ausência de acúleos foi determinada em indivíduos jovens de nove progênies de polinização livre provenientes de três árvores do fenótipo com acúleos e seis árvores do fenótipo sem acúleos. Calculou-se o índice de Shannon $(I)$, diversidade genética de Nei $(H e)$, porcentagem de bandas polimórficas $(P)$ e identidade genética de Nei. A ausência de acúleos (77\%) foi superior a presença de acúleos (23\%). A predominância 
do fenótipo ausência de acúleos e os índices moderados de diversidade genética $(P=64 \% ; H e=0,208$ e $I=0,315)$ entre os indivíduos com este fenótipo podem ser decorrentes do efeito da seleção artificial para o fenótipo ausência de acúleos da população fonte.

Palavras-chave: Floresta tropical sazonalmente seca; Melhoramento florestal; Marcador molecular; Fenótipo; Inter Simple Sequence Repeat.

\begin{abstract}
Mimosa caesalpiniifolia Benth. (Fabaceae) is a tree native to the semiarid region of Northeast Brazil, which presents growing economic potential for the exploitation of timber and non-timber forest products. The presence of aggressive prickles in most plants of this species makes it difficult to manage the stands, but there are specimens without prickles that can be used to get around this inconvenience. Our objective was to determine the phenotypic frequency of the character absence/presence of prickles in progenies of free pollination of a cultivated population of $M$. caesalpiniifolia, and to access the genetic diversity of individuals of the phenotype without prickles of this population. Genetic diversity was accessed using molecular markers Inter Simple Sequence Repeat (ISSR) and phenotyping for the presence/absence of prickles was determined in young individuals from nine free-pollination progenies from three phenotype trees with prickles and six phenotype trees without prickles. The Shannon index $(I)$, Nei genetic diversity $(\mathrm{He})$, percentage of polymorphic bands $(P)$ and Nei genetic identity were calculated. The absence of prickles $(77 \%)$ was higher that presence prickles $(23 \%)$. The predominance of the absence of prickles phenotype and the moderate levels of genetic diversity $(P=64 \% ; H e=0.208$ and $I=0.315)$ among individuals with this phenotype may be because of artificial selection for the absence of prickles phenotype in the source population.
\end{abstract}

Keywords: Seasonally dry tropical forest; Forest improvement; Molecular marker; Phenotype; Inter Simple Sequence Repeat.

\title{
Resumen
}

Mimosa caesalpiniifolia Benth. (Fabaceae) es un árbol originario de la región semiárida del noreste de Brasil que tiene un potencial económico creciente para la explotación de productos forestales maderables y no maderables. La presencia de espinas agresivos en la mayoría de estas plantas dificulta el manejo de los rodales, pero existen ejemplares sin espinas que pueden servir para sortear este inconveniente. El objetivo fue determinar la frecuencia fenotípica del carácter ausencia/presencia de espinas en progenies de polinización libre de una población cultivada de M. caesalpiniifolia, y acceder a la diversidad genética de individuos del fenotipo sin espinas de esta población. Se accedió a la diversidad genética mediante marcadores moleculares Inter Simple Sequence Repeat (ISSR) y se determinó el fenotipo de presencia/ausencia de espinas en individuos jóvenes de nueve progenies de polinización libre de tres árboles fenotípicos con espinas y seis árboles fenotípicos sin espinas. Se calculó el índice de Shannon $(I)$, la diversidad genética de Nei $(\mathrm{He})$, el porcentaje de bandas polimórficas $(P)$ y la identidad genética de Nei. La frecuencia del fenotipo sin espinas $(77 \%)$ fue superior a la del fenotipo con espinas (23\%). El predominio de la ausencia de fenotipo de espinas y los niveles moderados de diversidad genética $(P=64 \% ; H e=0,208$ e $I=0,315)$ entre individuos con este fenotipo puede deberse al efecto de la selección artificial por la ausencia de espinas en el fuente de población.

Palabras clave: Bosque tropical estacionalmente seco; Mejoramiento forestal; Marcador molecular; Fenotipo; Inter Simple Sequence Repeat.

\section{Introdução}

Mimosa caesalpiniifolia Benth. (Fabaceae) é uma leguminosa arbórea nativa da região semiárida do Nordeste do Brasil que apresenta potencial econômico crescente para exploração de produtos florestais madeireiros e não-madeireiros.

Além de ser cultivada comercialmente, esta espécie possui estudos avançados sobre o aproveitamento tecnológico da madeira, incluindo a durabilidade natural (Araujo \& Paes, 2018), resistência natural ao ataque de cupins xilófagos (Alencar, Paes, Bakke \& Silva, 2011) e caracterização e rendimento do carvão (Lins et al., 2020). Nas florestas onde ocorre naturalmente contribui na assimilação de compostos nitrogenados por meio da simbiose com bactérias fixadoras de nitrogênio (Martins et al., 2015) e no fornecimento de recursos alimentares para polinizadores entomológicos (Döhler \& Pina, 2017).

Embora a maioria dos indivíduos de $M$. caesalpiniifolia apresentam ramos com acúleos agressivos, uma baixa frequência de exemplares com ausência de acúleos ainda pode ser encontrada em populações naturais (Lima et al., 2008). Nas últimas duas décadas, a formação de povoamentos comerciais de $M$. caesalpiniifolia com indivíduos com ausência de acúleos tem sido incentivada, pois além de facilitar o trânsito de animais e trabalhadores no interior do povoamento (Lima et al., 2008), 
também apresentam madeira mais resistente a cupins xilófagos subterrâneos quando comparada ao fenótipo que apresenta acúleos (Alencar et al., 2011).

A multiplicação de M. caesalpiniifolia com ausência de acúleos pode ser realizada por via sexuada, pois segundo Carvalho, Maia e Amorim (1990) o cruzamento entre indivíduos com ausência de acúleos gera 100\% de descendentes com ausência de acúleos. Entretanto, não existem muitas informações sobre a produção de sementes de M. caesalpiniifolia com ausência de acúleos, mas acredita-se que sejam provenientes de plantios formados por poucos indivíduos ou clones, e por isso, provavelmente, possuem uma base genética estreita.

Quando a população é pequena e a variação genética intrapopulacional é estreita, aumenta-se a possibilidade de cruzamentos consanguíneos, resultando na manifestação de depressão por endogamia e isso prejudica a capacidade da descendência da população em se adaptar às mudanças bióticas e abióticas (Ingvarsson \& Dahlberg, 2018). Assim é desejável que tanto as áreas de coleta de sementes quanto às coleções de germoplasma usadas para melhoramento genético possuam alta diversidade genética (Pritchard et al., 2014; Silva-Júnior, Souza, Pereira \& Miranda, 2017).

Diante do exposto, o presente estudo objetivou determinar a frequência fenotípica do caráter ausência/presença de acúleos em progênies de polinização livre de uma população cultivada de $M$. caesalpiniifolia e acessar a diversidade genética de indivíduos com ausência de acúleos desta população.

\section{Metodologia}

\subsection{Caracterização da população e amostragem}

O presente estudo apresenta natureza quali-quantitativo (Pereira, Shitsuka, Pereira \& Shitsuka (2018). O mesmo foi desenvolvido em uma população fonte de M. caesalpiniifolia (5'53'52,5" S e 35²1'31,6" W) localizada no município de Macaíba, estado do Rio Grande do Norte, Brasil. Esta população era constituída por 355 indivíduos plantados em 2010 a partir de sementes de polinização livre coletadas apenas em indivíduos com ausência de acúleos de uma população plantada. Foi utilizado o espaçamento de 2,0 x 2,0 m no plantio, totalizando uma densidade populacional de 2.500 indivíduos ha-1 $^{-1}$ Em 2013 foram amostradas nove árvores (genitores) que se destacavam por apresentarem elevada produção de frutos em relação às demais, sendo três com presença de acúleos $(1,2$ e 5) e seis com ausência de acúleos (3, 4, 6, 7, 8 e 9).

\subsection{Avaliação fenotípica da presença/ausência de acúleos}

As sementes de cada árvore foram submetidas ao tratamento para superação da dormência (desponte na região oposta à micrópila) conforme as recomendações prescritas por Brasil (2013) e semeadas em um canteiro. O delineamento estatístico utilizado foi o de blocos casualizados, sendo quatro blocos com 25 sementes de cada árvore.

Aos 90 dias após a semeadura foi realizada a fenotipagem dos indivíduos quanto a presença e ausência de acúleos, sendo a frequência de cada fenótipo expressa em porcentagem. Os aspectos do caule de plantas com presença e ausência de acúleos estão apresentados na Figura 1 A e B, respectivamente. 
Figura 1 - Caule de plantas jovens de $M$. caesalpiniifolia com a presença de acúleos (A) e ausência de acúleos (B).

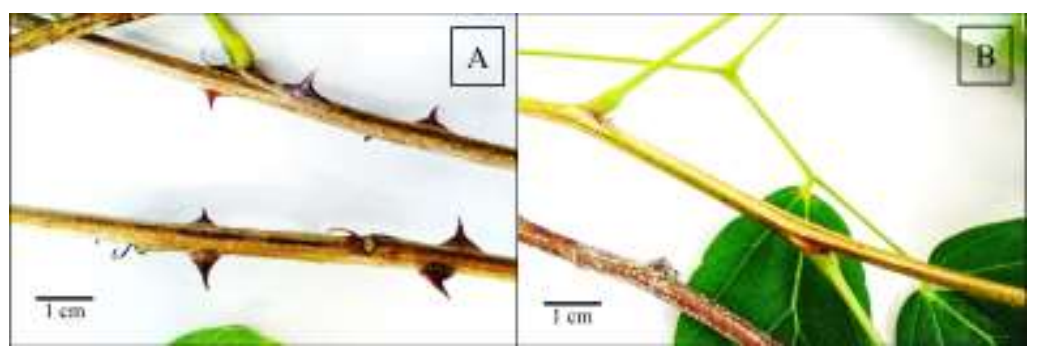

Fonte: Autores.

\subsection{Diversidade genética de indivíduos sem acúleos}

Treze indivíduos com ausência de acúleos foram amostrados aleatoriamente entre todos os indivíduos das progênies de polinização livre. Destes indivíduos, coletaram-se amostras de material foliar para extração de DNA genômico que foi realizado por meio de um protocolo adaptado a partir da metodologia de Doyle e Doyle (1987).

A quantificação e a pureza do DNA foram analisadas em espectrofotômetro de microplacas (Epoch ${ }^{\mathrm{TM}}$ ) e a integridade do material genético foi determinada por eletroforese horizontal em gel de agarose a 1,0\%. Este método de extração mostrouse adequado, pois a quantidade média de DNA obtida foi de 1.344,0 ng $\mu \mathrm{L}^{-1}$ com razão entre absorbâncias (260/280) de 1,99 com a formação de fragmentos com alta resolução no gel de agarose.

A amplificação de DNA foi realizada por PCR convencional usando sete primers ISSR do conjunto \#9 da Nucleic Acid-Protein Service Unit (University of British, Columbia, EUA): 807 (AG)8T, 824 (TC)8G, 827 (AC)8G, 840 (GA)8YT, 851 (GT)8YG, 873 (GACA)4 e 881 (GGGGT)3 recomendados por Araújo et al. (2016) para estudar a diversidade genética em M. caesalpiniifolia, cujas sequências de nucleotídeos estão apresentadas na Tabela 1.

Tabela 1 - Sequência de nucleotídeos (5'-3') de sete primers ISSR utilizados para acessar a diversidade genética em $M$. caesalpiniifolia.

\begin{tabular}{cc}
\hline Primer ISSR & Sequência (5'-3’) \\
\hline $807(\mathrm{AG}) 8 \mathrm{~T}$ & AGAGAGAGAGAGAGAGT \\
$824(\mathrm{TC}) 8 \mathrm{G}$ & TCTCTCTCTCTCTCTCG \\
$827(\mathrm{AC}) 8 \mathrm{G}$ & ACACACACACACACACG \\
$840(\mathrm{GA}) 8 \mathrm{YT}$ & GAG AGAGAGAGAGAGAYT \\
$851(\mathrm{GT}) 8 \mathrm{YG}$ & GTGTGTGTGTGTGTGTYG \\
$873(\mathrm{GACA}) 4$ & GACAGACAGACAGACA \\
$881(\mathrm{GGGGT}) 3$ & GGGTGGGGTGGGGTG \\
\hline
\end{tabular}

Nota: $\mathrm{Y}=\mathrm{C}$ ou T. Fonte: Autores.

As reações de amplificação foram preparadas considerando-se um volume final de 12,0 $\mu \mathrm{L}$. Cada reação continha 20,0 ng de DNA molde, 0,33 $\mu \mathrm{M}$ de primer; 1x de tampão de PCR (Phoneutria ${ }^{\circledR}$ ); 0,25 mg.mL ${ }^{-1}$ de $\mathrm{BSA}_{2}$ 2,0 mM de $\mathrm{MgCl}_{2}$; 0,25 mM de dNTP; 0,5 U de Taq DNA polimerase (Phoneutria ${ }^{\circledR}$ ) e água ultrapura. A amplificação do DNA foi realizada em termociclador (Veriti ${ }^{\circledR}$ ) sob as seguintes condições: desnaturação inicial a $94{ }^{\circ} \mathrm{C}$ por 2 min, seguido por 37 ciclos de $15 \mathrm{~s}$ a 94 ${ }^{\circ} \mathrm{C}$ para desnaturação, $30 \mathrm{~s} \mathrm{a} 47^{\circ} \mathrm{C}$ para anelamento do primer e $60 \mathrm{~s}$ a $72{ }^{\circ} \mathrm{C}$ para extensão da fita de DNA. Ao final dos 37 ciclos foi realizada uma extensão final a $72{ }^{\circ} \mathrm{C}$ por 7 min, seguido de resfriamento até atingir $4{ }^{\circ} \mathrm{C}$. 
Aos amplicons adicionaram-se os corantes GelRed $^{\mathrm{TM}}$ e Azul de Bromofenol (0,01\%) que em seguida foram aplicados em gel de agarose $\left(1,5 \% \mathrm{~m} \cdot \mathrm{v}^{-1}\right)$ com tampão de corrida TAE $1 \mathrm{X}$ (Tris-Acetato-EDTA). A voltagem aplicada foi de $100 \mathrm{v}$ e o tempo de migração dos fragmentos foi de 180 min. Um padrão de peso molecular de 1.000 pares de base (K181 DNA Ladder Invitrogen ${ }^{\circledR}$ ) foi utilizado. Os fragmentos de DNA no gel (bandas) foram fotodocumentados em um transiluminador UV.

As bandas geradas por cada primer foram classificadas como monomórficas e polimórficas e sua presença/ausência computada para todos os indivíduos. Os dados de presença/ausência das bandas foram organizados em uma matriz binária $(1=$ presença e $0=$ ausência) que foi utilizada para determinar os índices de diversidade genética implementados no software POPGENE (Population Genetic Analysis) versão 1.32 (Yeh, Boyle \& Xiyan, 1999), incluindo: índice de Shannon (I) (Lewontin, 1972), diversidade genética de Nei $(H e)$, porcentagem de bandas polimórficas $(P)$ e identidade genética de Nei (Nei, 1973; Nei, 1978). Posteriormente, calculou-se o conteúdo de informação polimórfica (PIC) para cada primer de acordo com Botstein, White, Skolnick \& Davis (1980).

Com os valores de identidade genética de Nei, confeccionou-se um dendrograma de similaridade baseados no método de agrupamento Unweighted Pair-Group Method Arithmetic Average (UPGMA) por meio do programa NTSYS-pc versão 2.1 (Rholf, 2000), adotando-se o valor médio da identidade genética de Nei como ponto de corte.

\section{Resultados e Discussão}

Na Tabela 2 estão apresentadas as frequências fenotípicas dos indivíduos de nove progênies de polinização livre de $M$. caesalpiniifolia. Verificou-se que em todas as progênies ocorreram indivíduos de ambos os fenótipos, mas com frequência variável tanto dentro quanto entre as progênies. O fenótipo ausência de acúleos variou de 52 a $84 \%$ com valor médio de $77 \%$, enquanto a presença de acúleos variou de 16 a 48\%, com valor médio de $23 \%$ (Tabela 2).

Tabela 2 - Frequência fenotípica do caráter ausência/presença de acúleos em nove progênies de polinização livre de $M$. caesalpiniifolia.

\begin{tabular}{ccccc}
\hline \multirow{2}{*}{ Progênie } & Fenótipo & $n$ & \multicolumn{2}{c}{ Frequência fenotípica dos indivíduos (\%) } \\
\cline { 3 - 5 } & & Ausência de acúleos & Presença de acúleos \\
\hline 1 & Presença de acúleos & 73 & 52 & 48 \\
3 & Presença de acúleos & 80 & 73 & 27 \\
4 & Ausência de acúleos & 75 & 84 & 16 \\
5 & Ausência de acúleos & 80 & 83 & 27 \\
6 & Presença de acúleos & 78 & 73 & 29 \\
7 & Ausência de acúleos & 75 & 71 & 29 \\
8 & Ausência de acúleos & 72 & 71 & 17 \\
9 & Ausência de acúleos & 82 & 83 & 30 \\
\hline Média & Ausência de acúleos & 67 & 70 & 23 \\
\hline
\end{tabular}

Nota: $n$ = número de indivíduos em cada família. Fonte: Autores.

A ausência de acúleos foi predominante na maioria das progênies, o que pode ser decorrente da elevada proporção deste fenótipo na população fonte que era constituída por $67 \%$ de árvores com ausência de acúleos. Este fato parece ser característico de populações melhoradas que sofreram seleção para o caráter ausência de acúleos, pois Lima et al. (2008) 
observaram que uma população cultivada e selecionada para ausência de acúleos produziu uma descendência com 71,5\% de indivíduos com ausência de acúleos, mas em uma população silvestre apenas 2,5\% dos indivíduos da descendência apresentavam acúleos.

A ausência de acúleos em M. caesalpiniifolia é um caráter recessivo provavelmente controlado por um ou poucos genes (Carvalho et al., 1990). Isso quer dizer que o fenótipo sem acúleos se expressará quando o alelo recessivo estiver em homozigose, enquanto o fenótipo com acúleos se expressará sempre que o alelo dominante estiver presente, ou seja, em homozigose ou heterozigose. Partindo desse pressuposto, acredita-se que esteja ocorrendo cruzamentos entre árvores com ausência e presença acúleos na população fonte, pois em todas as progênies derivadas de árvores com ausência de acúleos foram encontradas descendentes com presença de acúleos.

Devido a cruzamentos aleatórios, essas frequências fenotípicas provavelmente poderão diferir em eventos reprodutivos posteriores. Contudo, a ausência de acúleos certamente irá predominar na descendência desta população fonte em eventos reprodutivos posteriores devido a elevada frequência de árvores com este fenótipo na população (67\%).

$\mathrm{Na}$ Tabela 3 está apresentado o perfil de amplificação de sete primers ISSR usando treze indivíduos de $M$. caesalpiniifolia do fenótipo com ausência de acúleos. O perfil de amplificação de todos os primers ISSRs foi satisfatório, com número de bandas por primer variando de 8 a 11, com valor médio de 9; polimorfismo variando de 27 a 100\% com média de 63\%; e valores de PIC variando de 0,284 a 0,499, com valor médio de 0,408 (Tabela 3). Os primers UBC 807, 824 e 881 apresentaram os maiores valores de PIC e de bandas polimórficas.

Tabela 3 - Perfil de amplificação de sete primers ISSR para uma amostra de 13 indivíduos de M. caesalpiniifolia sem acúleos.

\begin{tabular}{cccc}
\hline Primer & Bandas & Bandas polimórficas (\%) & PIC \\
\hline UBC 807 (AG)8T & 10 & 80 & 0,465 \\
UBC 824 (TC)8G & 9 & 89 & 0,488 \\
UBC 827(AC)8G & 8 & 38 & 0,294 \\
UBC 840(GA)8YT & 8 & 63 & 0,458 \\
UBC 851(GT)8YG & 9 & 44 & 0,306 \\
UBC 873 (GACA)4 & 11 & 27 & 0,355 \\
UBC 881 (GGGGT)3 & 10 & 100 & 0,499 \\
\hline Total & 65 & - & - \\
\hline Média & 9,0 & 63 & 0,409 \\
\hline
\end{tabular}

Nota: $\mathrm{Y}=\mathrm{C}$ ou T. Fonte: Autores.

Esse padrão de amplificação se assemelha ao observado por Araújo et al. (2016) em um estudo anterior com $M$. caesalpiniifolia. Além disso, o número de bandas amplificadas neste estudo (65 bandas) superou o número mínimo requerido para acessar a diversidade genética desta espécie (51 bandas), como demonstraram Araújo et al. (2016) utilizando a análise de bootstrap. Dessa forma, o conjunto de primers utilizado no presente estudo também foi considerado satisfatório para acessar a diversidade genética da amostra de indivíduos analisada.

Os índices de diversidade genética ( $P=64 \%, H e=0,208$ e $I=0,315)$ e a identidade genética média $(0,768)$ revelaram que diversidade e divergência genética dos indivíduos com ausência de acúleos foram moderados. Isso pode ser um dos efeitos da seleção genética para o caráter ausência de acúleos realizada na população fonte, pois segundo Ingvarsson \& Dahlberg 
(2018), a seleção fenotípica no ciclo reprodutivo e durante a produção de sementes e mudas podem ter efeitos sobre a variação genética presente em uma espécie.

Além disso, a domesticação de $M$. caesalpiniifolia é recente, aproximadamente três décadas, tendo a seleção para fenótipo com ausência de acúleos direcionado para a diferenciação da primeira variedade melhorada da espécie. Esse processo de seleção e domesticação, normalmente envolvem mudanças substanciais na diversidade e estrutura genética populacional como mostram os estudos de investigação de eventos de domesticação de espécies arbóreas como Neolamarckia cadamba (Roxb.) Bosser (Rubiaceae) (Yiing, Fu, Seng \& Ling, 2014), Prunus persica L. Batsch (Rosaceae) (Akagi, Hanada, Yaegaki, Gradziel \& Tao, 2016) e Cerasus pseudocerasus (Lindl.) G. Don (Rosaceae) (Zhang et al., 2018) e isto pode ter ocorrido com a população fonte de $M$. caesalpiniifolia aqui estudada.

Na Figura 2 está apresentado a similaridade entre treze indivíduos com ausência de acúleos. Os valores de identidade genética entre os pares de indivíduos variaram de 0,646 a 0,892, com valor médio de 0,768 indicando similaridade moderada entre os indivíduos, que parece ser congruente com os parâmetros de diversidade genética (Figura 2). De acordo com a análise de agrupamento UPGMA, os indivíduos foram alocados em dois grupos de similaridade genética, sendo um dos grupos constituído por dez indivíduos e o segundo grupo por três indivíduos (Figura 2).

Figura 2 - Análise de agrupamento UPGMA de treze indivíduos sem acúleos de $M$. caesalpiniifolia baseada na identidade genética de Nei.

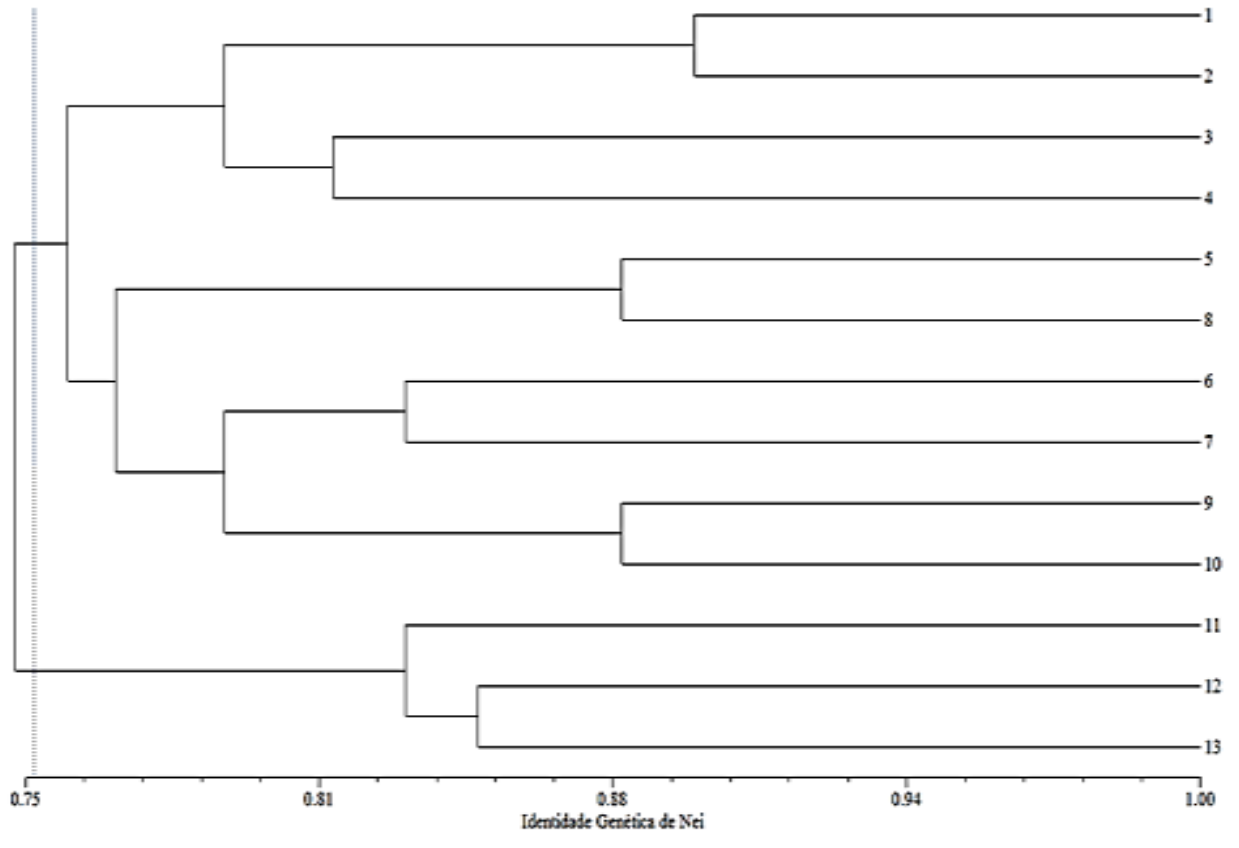

Fonte: Autores.

Esses resultados indicam que os indivíduos com ausência de acúleos divergem geneticamente entre si. Essa variabilidade poderá ser explorada em programas de melhoramento genético e formação de pomares de sementes de $M$. caesalpiniifolia com ausência de acúleos. Contudo, para ampliar ainda mais a base genética de germoplasma de $M$. caesalpiniifolia do fenótipo sem acúleos recomenda-se que sejam investigadas novas fontes de variabilidade provenientes de populações de origem melhorada ou silvestre. 


\section{Conclusão}

A predominância do fenótipo com ausência de acúleos e os índices moderados de diversidade genética entre os indivíduos de . caesalpiniifolia com este fenótipo podem ser decorrentes do efeito da seleção artificial para o fenótipo ausência de acúleos na população fonte. Estudos futuros ainda são necessários para compreender melhor a expressão do caráter ausência/presença de acúleos em M. caesalpiniifolia.

\section{Agradecimentos}

O presente trabalho foi realizado com apoio do Conselho Nacional de Desenvolvimento Científico e Tecnológico (CNPq) e da Coordenação de Aperfeiçoamento de Pessoal de Nível Superior - Brasil (CAPES) - Código de Financiamento 001 em acordo com a Fundação de Amparo à Pesquisa do Rio Grande do Norte (FAPERN).

\section{Referências}

Akagi, T., Hanada, T., Yaegaki, H., Gradziel, T. M., \& Tao, R. (2016). Genome-wide view of genetic diversity reveals paths of selection and cultivar differentiation in peach domestication. DNA Research, 23 (3), 271-282. https://doi.org/10.1093/dnares/dsw014

Alencar, F. H. H., Paes, J. B., Bakke, O. A., \& Silva, G. S. da. (2011). Wood natural resistance of Mimosa caesalpiniifolia Benth. to subterranean termites. Revista Caatinga, 24 (1), 57-64. https://periodicos.ufersa.edu.br/index.php/caatinga/article/view/1531

Araújo, F. dos, S., Pacheco, M. V., Vieira, F. de, A., Ferrari, C. dos, S., Félix, F. C., \& Chagas, K. P. T das. (2016). ISSR molecular markers for the study of the genetic diversity of Mimosa caesalpiniaefolia Benth. Idesia, 34 (3), 47-52. http://dx.doi.org/10.4067/S0718-34292016000300007

Araujo, J. B. S., \& Paes, J. B. (2018). Natural wood resistance of Mimosa caesalpiniifolia in field testing. Floresta e Ambiente, 25 (2), e20150128. https://doi.org/10.1590/2179-8087.012815

Botstein, D., White, R. L., Skolnick, M., \& Davis, R. W. (1980). Construction of a genetic linkage map in man using restriction fragment length polymorphisms. The American Journal of Human Genetics, 32 (3), 314-331. https://www.ncbi.nlm.nih.gov/pmc/articles/PMC1686077/

Brasil. Ministério da Agricultura, Pecuária e Abastecimento. (2013). Instruções para Análises de Sementes de Espécies florestais. Brasília: MAPA/ACS. https://www.gov.br/agricultura/pt-br/assuntos/laboratorios/arquivos-publicacoes-laboratorio/florestal_documento_pdf-ilovepdf-compressed.pdf/view

Carvalho, J. H. de, Maia, C. M. N. A., \& Amorim, G. C. de. (1990). Seleção de sabiá (Mimosa caesalpiniaefolia Benth.), leguminosa madeireira e forrageira, para obtenção de plantas sem acúleos. Mossoró: ESAM Coleção Mossoroense.

Döhler, T. L., \& Pina, W. da, C. (2017). Flower-visiting bees (Hymenoptera: Apoidea) of sabiá (Mimosa Caesalpiniifolia Benth.) in Teixeira de Freitas, Bahia, Brazil. Scientia Plena, 13 (8), 088001-1. https://doi.org/10.14808/sci.plena.2017.088001

Doyle, J. J., \& Doyle, J. L. (1987). Isolation of plant DNA from fresh tissue. Focus, 12, 13-15.

Ingvarsson, P. K., \& Dahlberg, H. (2019). The effects of clonal forestry on genetic diversity in wild and domesticated stands of forest trees. Scandinavian Journal of Forest Research, 34 (5), 370-379. https://doi.org/10.1080/02827581.2018.1469665

Lewontin, R. C. (1972). Testing the theory of natural selection. Nature, 236, 181-182. https://doi.org/10.1038/236181a0

Lima, I. C. A. R. de, Lira, M. de, A., Mello, A. C. L. de, Santos, M. V. F. dos, Freitas, E. V. de, \& Ferreira, R. L. C. (2008). Avaliação de sabiazeiro (Mimosa caesalpiniaefolia Benth.) quanto a acúleos e preferência por bovinos. Revista Brasileira de Ciências Agrárias, 3 (3), $289-294$. https://doi.org/10.5039/agraria.v3i3a345

Lins, T. R. da, S., Braz, R. L., Souza-Junior, C. C. G. C. de, Correia, H. T. V., Silva, T. C., \& Walter, L. S. (2020). Yield and characterization of charcoal from Mimosa caesalpiniifolia Benth. branches. Biofix Scientific Journal, 5 (1), 39-43. http://dx.doi.org/10.5380/biofix.v5i1.67394

Martins, P. G. S., Lira-Junior, M. A., Fracetto, G. G. M., Silva, M. L. R. B. da, Vincentin, R. P., \& Lyra, M. do, C. C. P de. (2015). Mimosa caesalpiniifolia rhizobial isolates from different origins of the Brazilian Northeast. Archives of Microbiology, 197, 459-469. https://doi.org/10.1007/s00203-014-1078-8

Nei, M. (1973). Analysis of gene diversity in subdivided populations. Proceedings of the National Academy of Sciences of the United States of America, 70 (12), 3321-3323. https://doi.org/10.1073/pnas.70.12.3321

Nei, M. (1978). Estimation of average heterozygosity and genetic distance from a small number of individuals. Genetics, 89, 90-583. https://www.genetics.org/content/89/3/583

Pereira, A. S., Shitsuka, D. M., Parreira, F. J., \& Shitsuka, R. (2018). Metodologia da pesquisa científica. UFSM. https://repositorio.ufsm.br/bitstream/handle/1/15824/Lic_Computacao_Metodologia-Pesquisa-Cientifica.pdf?sequence=1 
Research, Society and Development, v. 10, n. 3, e19110313096, 2021

(CC BY 4.0) | ISSN 2525-3409 | DOI: http://dx.doi.org/10.33448/rsd-v10i3.13096

Pritchard, H. W., Moat, J. F., Ferraz, J. B. S., Marks, T. R., Camargo, J. L. C., Nadarajan, J., \& Ferraz, I. D. K. (2014). Innovative approaches to the preservation of forest trees. Forest Ecology and Management, 333 (1), 88-98. https://doi.org/10.1016/j.foreco.2014.08.012

Rohlf, F. J. (2000). NTSYS-pc: numerical taxonomy and multivariate analysis system, version 2.1. Exeter Software.

Silva-Júnior, A. L., Souza, L. C., Pereira, A. G., \& Miranda, F. D. (2017). Genetic diversity of Schizolobium parahyba var. amazonicum (Huber ex. Ducke) Barneby, in a forest area in Brazil. Genetics and Molecular Research, 16 (3), e2017. https://doi.org/10.4238/gmr16039774

Yeh, F. C., Boyle, T. Y. Z., \& Xiyan, J. M. (1999). Popgene version 131: Microsoft Window-based freeware for population genetic analysis. Edmonton: Alberta.

Yiing, T. S., Fu, C. S., Seng, H. W., \& Ling, P. S. (2014). Genetic diversity of Neolamarckia cadamba using dominant DNA markers based on Inter-Simple Sequence Repeats (ISSRs) in Sarawak. Advances in Applied Science Research, 5 (3), 458-463.

Zhang, J., Chen, T., Wang, Y., Chen, Q., Sun, B., Luo, Y., Zhang, Y., Tang, H., \& Wang, X. (2018). Genetic diversity and domestication footprints of chinese cherry [Cerasus pseudocerasus (Lindl.) G. Don] as revealed by nuclear microsatellites. Frontiers in Plant Science, 9 (238), 01-13, 2018. https://doi.org/10.3389/fpls.2018.00238 